\title{
The Role of Strategic Vigilance in Applying the Porter Model of The Five Forces in A Sample of Private Hospitals
}

\author{
*Researcher: Habib Marouh Nasser Al-Yasiri, **Researcher: Ahmed Ghazi Mahdi Al-Yasiry, \\ \#Researcher: Asmaa Habib Nehme \\ *Wasit University / College of Business and Economics \\ **Ministry of Health \\ \#Al-Farabi University College
}

DOI: $10.37648 /$ ijrssh.v10i04.022

Received:15 $5^{\text {th }}$ October, 2020; Accepted:04 ${ }^{\text {th }}$ November, 2020; Published: 09 ${ }^{\text {th }}$ November, 2020

\begin{abstract}
The main purpose of this research is to recognize the importance of the role of strategic vigilance in the application of the Porter model. Strategic vigilance is one of the contemporary tools to provide organizations with all emerging information to ensure that they do not become obsolete in the environment within which they operate. The Porter model has become increasingly important in recent days Due to the escalation of competitive processes in the framework of the environment in which the organization operates.

Therefore, the research problem emphasized the lack of awareness of the importance of strategic vigilance in enhancing the knowledge of the administration on the application of the Porter model in their organization. Therefore, the importance of research in presenting a set of solutions to the problems facing these organizations as far as the variables are investigated, the questionnaire was adopted as a main tool for collecting research data, which was prepared on the basis of a number of readymade measurements after being subjected to tests of honesty and consistency to suit the current research trends. The health sector was chosen as a field of application, in addition, the statistical program (SPSS.V20) was used in the introduction and analysis of research data. The most important tools adopted in the analysis (arithmetic mean, standard deviation: to diagnose) The results of these tools have confirmed the validity of the hypotheses that emerged from the research. Therefore, the researchers recommended that the investigated organization should examine the experiences of the successful organizations. Insofar as it relates to the variables investigated in order to enhance the knowledge of the administrative leaders operating in them and thus improve the level of performance.
\end{abstract}

Key words: strategic vigilance, Porter model, hospitals, administrative leadership, environment

\section{INTRODUCTION}

Organizations are active in an environment characterized by continuous change and then it will be necessary to know its components and future trends. Therefore, Porter's Five Forces model contributes to providing an analysis of the competitive environment.
Therefore, organizations in all sectors are looking for ways to disclose their environment and ways to support their sources of information, and ways to nullify competitors' plans and have the largest market share. The organization's analysis of its external environment is necessary, which requires ownership Strategic vigilance being the most important means to face emergency conditions, and 
strategic vigilance aims to uncover hidden signals, potential changes and profound transformations, which are based on collecting, analyzing and disseminating appropriate and necessary information for decisionmaking, and it represents a competitive advantage for organizations. As strategic vigilance is one of the basic tasks in processing public information and data in all political, economic and social fields. For this purpose, the current research includes four chapters, the first topic deals with the methodology, and the second topic is devoted to presenting the theoretical framework of strategic awakening and the Porter model, while the third topic deals with the applied aspect of the research, and the research was concluded with the fourth study that presents the most important conclusions and recommendations reached by the researchers.

\section{THE FIRST TOPIC: RESEARCH METHODOLOGY}

This topic is devoted to the purpose of identifying the research problem, its most important objectives, and its scientific and practical importance, while trying to identify the tools for collecting and analyzing data and the limits of research, including the sample and the researched community, as in the following paragraphs:

\section{First: the research problem}

All organizations in our current era face a continuous momentum of environmental challenges and competitive conflicts between them as a result of the scarcity of economic resources, the rapid changes in working conditions, the development in the needs and desires of their customers and their transformation from one organization to another in search of the best, most appropriate and quality, which led these organizations to explore the depths of their external environment Through observation, anticipation, constant attention, and proactive identification of risk sites and obtaining information through which the most accurate and weak signals related to threats and opportunities are discovered to allow strategic decision-makers to act quickly and in a timely manner in pursuit of their goals, and therefore the research problem arises in the presence of a clear deficiency in paying attention to the concepts of strategic vigilance. And its role in providing the necessary information to implement Porter's model in the researched organization, and accordingly, a number of questions may arise from this problem, namely:
1. What is the importance of the strategic vigilance of the researched organization?

2. What is the degree of interest of the researched organization in applying Porter's model?

3. What is the nature of the correlation and influence relationship between the strategic vigilance and the Porter model in the researched organization?

\section{Second: The importance of research}

Strategic vigilance must be seen as one of the basic components of management. Through strategic vigilance, an effective organization can be established and the importance of research is evidenced by the following:

1. Strategic vigilance develops the ability of senior management to deal with environmental variables through rapid reactions according to the analysis of Porter's model.

2. Research derives its importance from the role that strategic vigilance plays as a basic resource on which successful organizations build their future.

3. Vigilance is considered a means for organizations to reveal their surroundings and search for means to support their sources of information and their ability to defend and attack.

\section{Third: Research objectives}

The current research seeks to achieve the following objectives:

Highlighting the strategic vigilance in light of the application of Porter's competitive model. Establishing a knowledge framework for the concept of Porter's model and its importance in analyzing the environment and providing information to the organization

\section{Fourth: Search scheme}

The independent variable search scheme dealt with strategic vigilance on dimensions, as well as the dependent variable included Porter's model on two dimensions. 


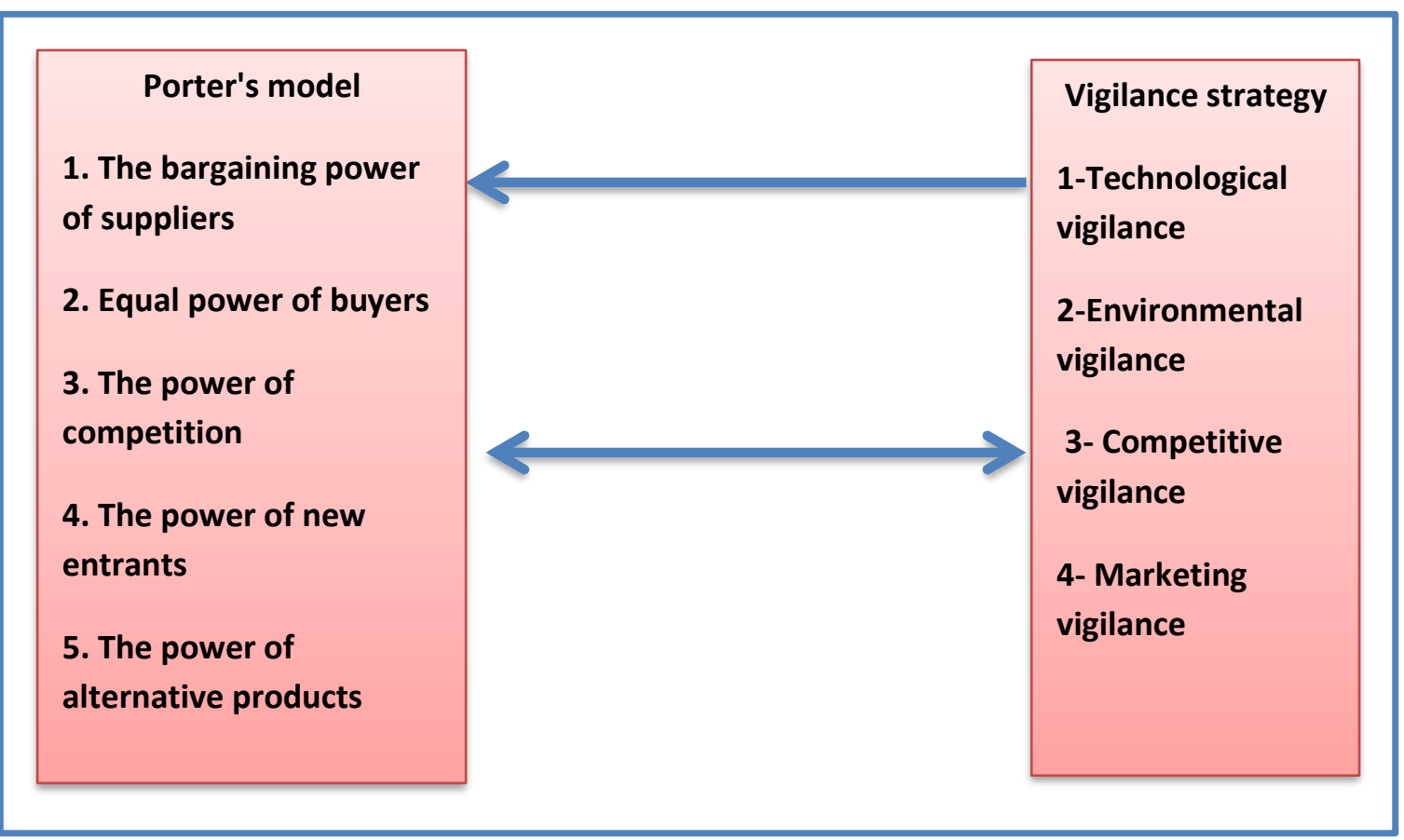

Figure (1) Hypothesis search scheme

Fifth: the research hypothesis

This research starts from two main hypotheses, namely: 1. The first main hypothesis: It states (there is a statistically significant relationship between strategic vigilance and the application of Porter's five forces model in the researched organization).

2. The second main hypothesis: It states (there is a statistically significant effect of strategic vigilance in the application of Porter's five forces model in the researched organization)

\section{Sixth: Research tools}

In order for the research to achieve its goals, the researcher relied on collecting data and information on the following tools: 1. Tools of the theoretical framework: The researcher relied on the scientific information available to writers and researchers related to the subject of the study, represented in books, letters, theses and research, as well as the use of the international network of the Internet through which the theoretical background was developed and addressed to serve the study. 2. Data collection tools: The questionnaire form was used as the questionnaire form was relied upon as the main tool for collecting data and measuring research variables. The questionnaire form is the main source for data collection because of its advantage in obtaining respondents 'responses to the research factors and their variables. The five-point Likert scale was used in developing the questionnaire.

3. Data analysis tools: The ready-made statistical program (SPSS.V20) was used in entering and analyzing the research data. It was used if both (arithmetic mean, standard deviation) were used to determine the reality and importance of the studied variables. Whereas, (Spearman's correlation coefficient and simple linear regression coefficient) were used to clarify the nature of the correlation and influence relationships between the studied variables and thus test the hypotheses of the research that started from them.

\section{Seventh: The research community and its sample}

The research community was represented by four private hospitals (Al-Fetal National Hospital, Al-Alweya National Hospital, Al-Beshara Private Hospital, and Al-Banks National Hospital). As for its sample, it included 30 department and division officials in these hospitals. 


\section{Eighth: Research limits}

Temporal boundaries: The temporal boundaries of the field and application aspect of research extended from $1 / 11 / 2018$

to

$1 / 31 / 2019$

Spatial boundaries: The spatial limits of the research were represented by four private hospitals. Human borders: heads of departments and people in charge of these hospitals.

\section{THE SECOND TOPIC: THE THEORETICAL SIDE}

First: vigilance Strategy: This paragraph has allocated for the purpose of identifying the strategic concept of vigilance and its dimensions and some topics related to them as in the following paragraphs:

\section{First -1: The concept of strategic vigilance and its objectives}

Strategic vigilance emerged as a result of research in strategic management that focuses on realistic and proactive information that organizations obtain from their surrounding environment. Writers and researchers have varied views on its concept, and their ideas differed according to their specializations and goals. It was referred to (Amira, 2012: 4) that it is not just a limited work with simple monitoring of the ocean, but rather it is voluntary work, as it is like radar that always seeks to anticipate the right time, and from the viewpoint of (Noor Al-Abidin, 2012: 52) it is an organization that seeks to know the business environment and anticipate changes. An informational process through which an organization is able to listen to its environment so that it can make decisions. As for (Hussein, 2015: 11), he emphasized that strategic vigilance is the process of observing and analyzing the environment that helps in disseminating, processing and selecting information for use in making strategic decisions. 328), and in almost the same direction, it was known as a complex organizational process aimed at ensuring the sustainability of the organization and the continuity of its activity, whereby it monitors any information or weak signal from its wide surroundings in order to allow this information to exploit opportunities and avoid threats (Mahmoud, 2017: 210), and according to the principles of analysis SWOT was defined as a set of activities and activities that enable organizations to collect, process and analyze information on all changes occurring in the organization's environment to identify opportunities, threats, strengths and weaknesses (Ibrahim, 2017: 29). The strategic vigilance also seeks to achieve the following goals according to the viewpoint (Ibrahim, 2017: 23):

1. Predicting opportunities and working to improve their exploitation and avoid threats and their impacts.

2. Diagnose and define the best practices that serve the organization and its strategies and ensure facing competition in the field of activity.

3. Achieving the overall efficiency of the strategic information system in the field of marketing.

4. Analyzing the operational, technical and technological environment of the organization.

5. Compare the organization's performance with its competitors and try to develop it.

6. Objective evaluation of its current and future competitive position.

7. Choose the appropriate project in the appropriate sector of activity.

\section{First: Characteristics of Strategic vigilance}

Strategic vigilance consists of a set of characteristics that distinguish it from others, and it also aims to achieve many goals (Hussein, 2015: 13).

1. Strategy: It is responsible for directing the organization fundamentally and comprehensively towards the future and is used to refer to all the information provided for vigil. It is not related to current and repeated operations and which has a model of models evaluated by experience, but rather is concerned with future decisions that have a significant impact on the competitiveness and survival of the organization.

2. Collective intelligence: It is a pre-emptive research process that depends on the intelligence of a group of individuals that work on selecting information related to the environment, observing signals, comparing them and giving them a specific meaning according to the rules and behavior of group work to reduce the uncertainty due to the accelerating changes that occur in the environment of the external organization.

3. Creation of creativity: Strategic awakening works to interpret the early warning signals that are related to the creativity component. Vigilance 
information does not describe the events that actually occurred, but through it, hypotheses and a proactive creative vision can be formulated (Mahmoud, 2017: 210).

4. Voluntary: Since strategic vigilance is of a creative nature, it cannot be limited to simply monitoring the environment. Rather, it needs a will that imposes on the organization's members to activate and open the ears and eyes well in order to proactively capture information.

5. Expectation: In the concept of strategic vigilance, the process of anticipation and the detection of changes that may occur in the vicinity of the organization becomes clear to us, and when testing a practical and theoretical result for the type of information, predictive features must appear and not express variables in the past and present only, but must provide clarifications about the future (Age, 2017: 328).

\section{First: Types of strategic vigilance}

The most prominent types of strategic vigilance can be identified in the following, which will be adopted as dimensions to be studied in the application side of this research, namely:

1. Competitive vigilance : It is the activity through which the organization gets to know its current and potential competitors, and it is also concerned with the environment in which the competing organization develops, and this is by gathering information from industry analysis and competition analysis, then analyzing and extracting results to be used in making appropriate decisions (Murad (2010: 133).

2. Marketing vigilance: Marketing vigilance is a series of continuous and repetitive processes through which the organization can monitor and analyze its marketing environment to obtain potential indicators related to opportunities and threats that affect the survival of the organization, and vigilance is used in making decisions aimed at improving the performance of the organization (Nour Al-Abidin, 2012: 52) and since marketing vigilance means the process of searching, collecting, processing and disseminating information related to the organization's market, through marketing vigilance, the organization can follow developments in the organization's markets, the organization's position in the market, consumer behavior and also the centers of advertising campaigns for competitors (Youssef, 2010: 14)

3. Environmental vigilance: this type of vigilance concerns the remaining elements in the environment of the organization that were not taken into account by the previous types, and it is also known as a comprehensive vigilance concerned with monitoring economic, political, legal, demographic and cultural developments (Morsi and Salim, 2007: 69) that affect one way or another. Last in the activity of the organization, and its implementation is a difficult task for the organization as it concerns a broad aspect of the remaining environment related to all events and developments in the fields of the environment (Omar, 2007: 133-132).

4. Technological vigilance: refers to the monitoring and analysis of the technological environment by the organization in order to identify opportunities and threats. It allows the organization to know new technologies related to its work activity and works to enhance competitiveness in the event of its exploitation by acquiring technological innovations (Hussein, 2015: 25).

Second: Porter's Model: In this paragraph we will get acquainted with the Porter model and its most important components, as follows:

Second - 1: the concept of Porter's model

(Porter Model) helps to understand the main forces that directly affect the organization. And the circumstances that define the shape of the industry, as well as the fact that management needs more information to practice its competitive strategic activity than it needs to assess the attractiveness and profitability of the industry. In order to develop effective competitive strategies, it is necessary to understand how the strategic levels relate to the organizational structure and the flexibility it enjoys to face environmental changes. The competitive strategies and behaviors of each organization differ from its competitors due to the different competitors in the characteristics of their products, and the degree of their focus on product quality, technology type, distribution channels and other characteristics. Consequently, organizations tend to 
respond to environmental factors in ways that are consistent with the subjective characteristics of the organization's management and the competitive strategy (Al-Sakal, 2004: 42). When analyzing the competitive environment in the industry, one must rely on the Porter model. This model includes five competitive forces in the industry that have proven their effectiveness since the seventies of the last century (Hussein, 2010: 19).

\section{Second: Elements of Porter's Five Forces Model}

Competitive forces in a particular industry are directly related to the interaction between five forces, and then a brief description of it will be given as in the following paragraphs:

1-Threat of new competitors in the industry: The entry of new members into the industry leads to competition with existing organizations for their share of market share. And there becomes intense competition for the resources that will be required in larger quantities, and then they represent a threat to the existing organizations (Ibrahim, 2006: 55). The new entrants to any industry bring new productive energy and new capabilities, such as the desire to obtain a market share or the largest amount of resources, so they pose a threat to the organization, so organizations place obstacles on the entry of other organizations into a specific industry (Hussein, 2010: 20)

2- Threats of alternative goods or services: Substitute commodities are defined as commodities that have the ability to replace the original goods completely or partially and are not competing goods (Ibrahim, 2006: 55) The effect of substitution on the profitability of the industry depends on a number of factors such as the availability of close alternatives, The cost of the substitute for the commodity users, the strictness of the producers of the substitute goods, the price and value tradeoffs between the original products and their substitutes of the goods.

3-The bargaining power of suppliers: suppliers can influence the industry through their ability to raise prices, reduce the quality of the commodity, or reduce the services associated with the product when the group of suppliers is strong. This is achieved when a small group of supplier's controls supplying companies with the materials needed for the industry. Replacements are not readily available. (Al-Jader, 2007: 26)
4- The bargaining power of buyers: Customers have bargaining power for each of them's desire to obtain the quantities they need in markets that are characterized by competition. They can obtain products from potential suppliers as customers negotiate to obtain the lowest prices.

5- The intensity of competition between existing organizations: These forces are among the five most influential forces in the organization. The organization may have opportunities for growth, but it faces intense competition between competitors and competition among competitors takes many forms such as lowering prices, introducing a new product, and advertising wars, and so on. Intense competition reduces industry profitability (Hamdan and Idris, 2009: 101).

\section{Third: The role of strategic vigilance in applying} Porter's model

When analyzing the organization's environment in the industry, one must rely on Porter's model, and understanding the industry's structure must be a starting point for strategic analysis. The five competitive forces reflect (Hussein, 2015: 37):

1. Threats of new entrants: They pose a threat to the organization, who bring new production capacity and new capabilities, such as the desire to obtain market share or the largest amount of resources.

2. Buyers' threats: Here, buyers use their power to reduce prices, that is, to demand higher quality and the same price. 3. Supplier Threats: Suppliers can influence the industry through their ability to raise prices or reduce the quality of the goods or services purchased from them.

4. Threats of competitors: Competition among competitors takes many forms such as lowering prices, introducing a new product, and advertising wars. Thus, intense competition will reduce the profitability of the industry. 5. Threats of alternatives: Some organizations offer alternatives that replace industrial products or services and create the same value-added for the customer.

The five forces define the most common threats facing organizations in their competitive environments and determine the conditions under which these threats are present to a high or low degree. These threats increase the costs of the organization and reduce its returns. The relationship of Porter's Five Forces and the types of vigils can be illustrated in Figure (2) 


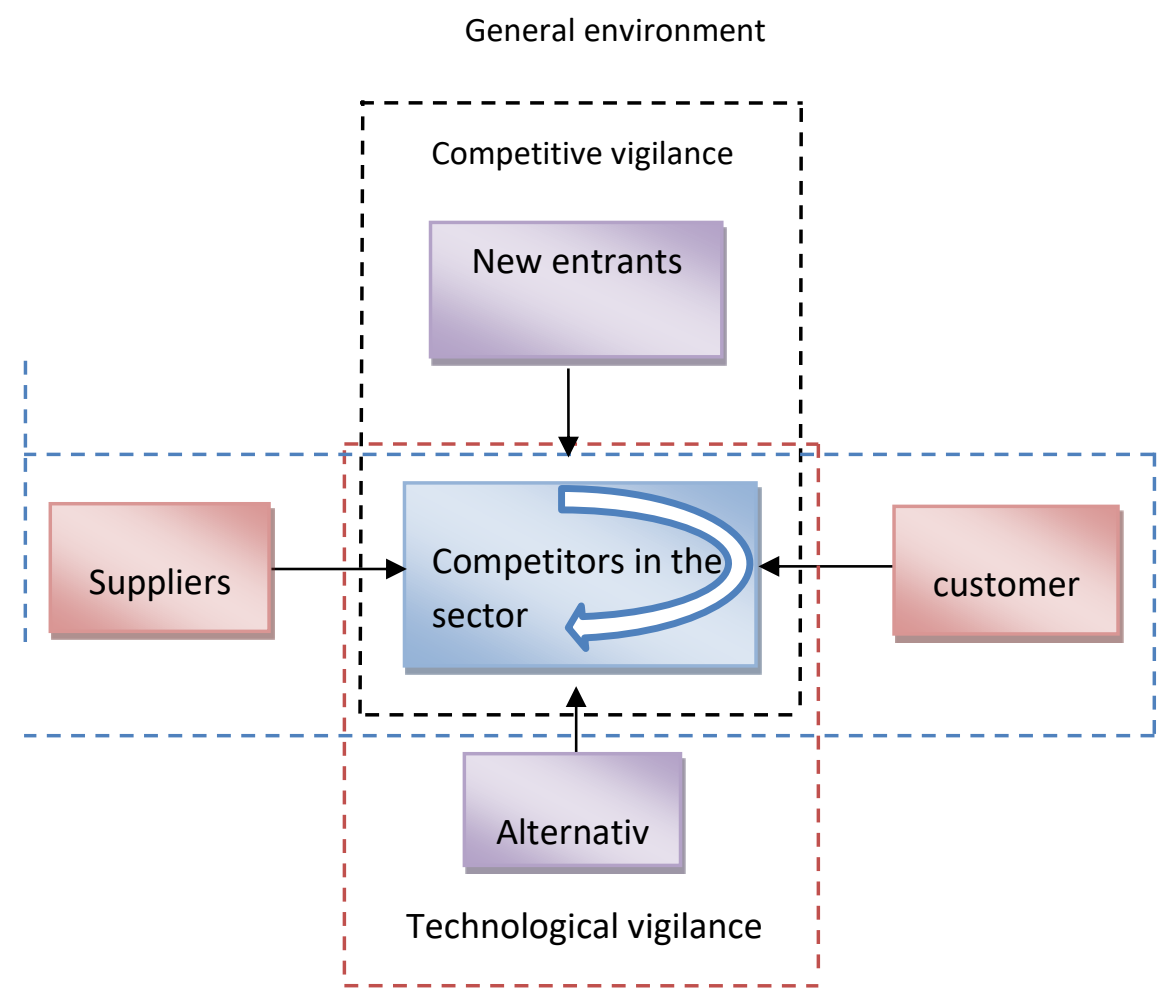

Figure (3) Porter's Five Forces Model of Competition with Types of Awakening Source: Nour El-Abidine, Goujil (2012) The role of strategic vigilance in rationalizing communication between the institution and its surroundings, a field study of the Sidi Arghis Oum El Bouaghi Mills Unit, MA thesis, Algeria, p. 33.

The third topic: the applied side

In this topic, a diagnosis of the reality and importance of the investigated variables will be carried out in addition to testing the hypotheses from which the research was launched, as in the following paragraphs:

First: Diagnosing the reality and importance of the variables discussed

The following tables show the most prominent results produced by the statistical tools used to diagnose the reality and importance of the studied variables, namely (the arithmetic mean, which was interpreted according to the following). If its value ranges between $1-1.80$, it means that the variable is very weak, between $1.81-2.60$ The variable is weak, between 2.61 - 3.40 The variable about the mean, i.e. neutral, between $3.41-4.20$, the variable is high, between $4.21-5$, the variable is very high \{, the standard deviation, and its results have been interpreted as follows $\}$ If its value is below 0.80 , this reflects a high harmony between the answers, if its value is between $0.80-0.90$ The harmony is good, but if it is above 1.0 , then this is acceptable harmony. \{. The interpretive variable (strategic alertness) was measured through four dimensions and the results were as follows: 
Table (1) shows the mean and standard deviation of the environmental vigilance items

\begin{tabular}{|l|l|l|}
\hline Paragraphs & mean & $\begin{array}{l}\text { standard } \\
\text { deviation }\end{array}$ \\
\hline The hospital administration works to monitor its surroundings by collecting data & 2.57 & 1.10 \\
\hline $\begin{array}{l}\text { The hospital administration relies on multiple sources to obtain information about } \\
\text { the external environment, such as interviews } \\
\text { and the Internet }\end{array}$ & 3.07 & 1.33 \\
\hline $\begin{array}{l}\text { The hospital administration is based on reducing environmental } \\
\text { pollution by using the correct methods of waste disposal }\end{array}$ & 2.32 & 1.12 \\
\hline Total environmental vigilance & 2.66 & 1.18 \\
\hline
\end{tabular}

We notice through the previous table that the environmental vigilance dimension achieved an arithmetic mean of (2.66), which is less than the hypothetical arithmetic means of (3) and indicates that the environmental alert dimension ranges around the value of the hypothetical mean, while the value of the standard deviation reached (1.18). Reflects the existence of an acceptable consistency between the answers of the research sample about the paragraphs of this dimension, and at the level of the sub-paragraphs, in paragraph (2) I obtained the highest arithmetic mean, which reached (3.07), which is higher than the hypothetical mean of (3) and with a standard deviation of (1.33) As for the lowest arithmetic mean, paragraph (4) obtained the lowest arithmetic mean, which was (2.32) and a standard deviation of (1.12). As for the results of the technological alertness dimension, they can be explained through Table (2):

Table (2) shows the mean and standard deviation of the Technological vigilance items

\begin{tabular}{|l|l|l|}
\hline Paragraphs & mean & $\begin{array}{l}\text { standard } \\
\text { deviation }\end{array}$ \\
\hline $\begin{array}{l}\text { The hospital administration is looking for scientific } \\
\text { discoveries in its field of specialization }\end{array}$ & $\mathbf{2 . 5 3}$ & $\mathbf{1 . 2 0}$ \\
\hline $\begin{array}{l}\text { The hospital uses the most modern medical equipment. } \\
\text { The hospital possesses research and development } \\
\text { capabilities in its field of specialization. }\end{array}$ & $\mathbf{3 . 0 7}$ & $\mathbf{1 . 3 8}$ \\
\hline $\begin{array}{l}\text { The hospital administration seeks to possess technology } \\
\text { that is difficult for its competitors to obtain. }\end{array}$ & $\mathbf{3 . 3 9}$ & $\mathbf{1 . 1 3}$ \\
\hline Total technological vigilance & $\mathbf{3 . 7 5}$ & $\mathbf{1 . 1 4}$ \\
\hline
\end{tabular}

It is evident from the previous table that the technological vigilance dimension achieved an arithmetic mean of (3.19) which is higher than the hypothetical arithmetic means and indicates that the technological alert dimension ranges around the value of the hypothesis mean, while the value of the standard deviation reached (1.21), it reflects the existence of an acceptable harmony. Among the responses of the research sample about the paragraphs of this dimension, and at the level of the subparagraphs, paragraph (4) got the highest arithmetic mean, which amounted to (3.75), which is a high mean and a standard deviation of (1.14). As for the lowest arithmetic mean, I got it Paragraph (1), which amounted to (2.53) and a standard deviation of (1.20). Table (3) shows the results of the competitive vigilance dimension as follows: 
Table (3) shows the mean and standard deviation of the competitive vigilance items

\begin{tabular}{|l|l|l|}
\hline Paragraphs & mean & $\begin{array}{l}\text { standard } \\
\text { deviation }\end{array}$ \\
\hline $\begin{array}{l}\text { The hospital administration is working to collect } \\
\text { Information on its competitors }\end{array}$ & $\mathbf{3 . 4 6}$ & $\mathbf{1 . 1 7}$ \\
\hline $\begin{array}{l}\text { Hospital management monitors changes in competitors' } \\
\text { strategies }\end{array}$ & $\mathbf{3 . 3 2}$ & $\mathbf{1 . 1 8}$ \\
\hline $\begin{array}{l}\text { The hospital administration is aware of the movements } \\
\text { of its new and existing competitors from governmental } \\
\text { and private hospitals }\end{array}$ & $\mathbf{3 . 2 8}$ & $\mathbf{1 . 2 4}$ \\
\hline The hospital administration monitors the new fields of competitors & $\mathbf{3 . 3 5}$ & $\mathbf{1 . 2 8}$ \\
\hline Total competitive vigilance & $\mathbf{3 . 3 5}$ & $\mathbf{1 . 2 2}$ \\
\hline
\end{tabular}

It is evident from Table (3) that the Competitive vigilance dimension achieved an arithmetic mean of (3.35) which is higher than the hypothetical arithmetic mean and indicates that this dimension ranges its value around the value of the hypothesis mean, while the value of the standard deviation reached (1.22) it reflects the existence of harmony Acceptable among the respondents of the research sample about the paragraphs of this dimension, and at the level of sub-paragraphs, paragraph (1) obtained the highest arithmetic mean of (3.46), which is a high mean and a standard deviation of (1.17). As for the lowest arithmetic mean, it was obtained Paragraph (3), which amounted to (3.28) and a standard deviation of (1.24). Through Table (4) it is possible to clarify the results of the analysis on the dimension of marketing vigilance

Table (4) shows the mean and standard deviation of the marketing vigilance items

\begin{tabular}{|l|l|l|}
\hline Paragraphs & mean & $\begin{array}{l}\text { standard } \\
\text { deviation }\end{array}$ \\
\hline $\begin{array}{l}\text { he hospital administration works to increase its growth } \\
\text { opportunities by providing quality health service. }\end{array}$ & $\mathbf{3 . 0 0}$ & $\mathbf{1 . 0 8}$ \\
\hline $\begin{array}{l}\text { The hospital administration seeks to gain the confidence of } \\
\text { its customers by providing continuous health services. }\end{array}$ & $\mathbf{3 . 0 7}$ & $\mathbf{1 . 1 1}$ \\
\hline $\begin{array}{l}\text { The hospital has all the resources and tools necessary to } \\
\text { provide them. }\end{array}$ & $\mathbf{3 . 6 9}$ & $\mathbf{1 . 0 9}$ \\
\hline $\begin{array}{l}\text { The hospital administration seeks to provide new health } \\
\text { services to its customers. }\end{array}$ & $\mathbf{3 . 0 3}$ & $\mathbf{1 . 2 3}$ \\
\hline Total marketing vigilance & $\mathbf{3 . 1 9}$ & $\mathbf{1 . 1 3}$ \\
\hline
\end{tabular}

We notice through Table (4) that the Competitive vigilance Dimension has achieved an arithmetic mean of (3.19) which is higher than the hypothetical arithmetic mean and indicates that the Competitive Awakening Dimension ranges around the value of the hypothesis mean, while the value of the standard deviation reached (1.13), it reflects the existence of Acceptable harmony between the responses of the respondents of the research sample about the paragraphs of this dimension, and at the level of sub-paragraphs, paragraph (3) obtained the highest arithmetic mean, which amounted to (3.64), which is a high arithmetic mean and with a standard deviation of (1.09). As for the lowest mean of my calculation, Paragraph (1) occurred, which amounted to (3.00) and with a standard deviation of (1.08). As for the total strategic alertness variable, it achieved an arithmetic mean of (3.11) which is higher than the hypothetical arithmetic mean and indicates that the dimension of strategic alertness in the researched organization ranges around the value of the hypothetical mean, while the value of the standard deviation reached (1.19), it reflects the existence of an acceptable harmony. Statistically, between the answers of the research sample about the paragraphs of this variable. With regard to the response variable (Porter's model), it was measured in five dimensions and the results were as follows: 
Table (5) shows the mean and the standard deviation of the degree of competition between organizations

\begin{tabular}{|l|l|l|}
\hline Paragraphs & mean & $\begin{array}{l}\text { standard } \\
\text { deviation }\end{array}$ \\
\hline $\begin{array}{l}\text { The hospital evaluates its performance by comparing it with } \\
\text { its competitors }\end{array}$ & 3.57 & $\mathbf{1 . 0 3}$ \\
\hline $\begin{array}{l}\text { There is a balance between competing hospitals in their ability } \\
\text { to acquire resources }\end{array}$ & $\mathbf{3 . 4 2}$ & $\mathbf{0 . 9 5}$ \\
\hline $\begin{array}{l}\text { The hospital has the basic requirements for competition to meet } \\
\text { the competitive challenges of Arab and foreign hospitals }\end{array}$ & $\mathbf{3 . 6 4}$ & $\mathbf{0 . 9 5}$ \\
\hline Total degree of competition between organizations & $\mathbf{3 . 5 4}$ & $\mathbf{0 . 9 7}$ \\
\hline
\end{tabular}

It is evident from Table (5) that the dimension of the degree of competition between organizations achieved an arithmetic mean of (3.54) which is higher than the hypothetical arithmetic mean and indicates that this dimension exists with a high degree in the researched organization, while the value of the standard deviation reached (0.97), it reflects There is an acceptable good presence among the responses of the respondents of the research sample about the paragraphs of this dimension, and at the level of sub-paragraphs, paragraph (3) obtained the highest arithmetic mean, which amounted to (3.64), which is a high medium with a standard deviation of (0.95), while the lowest arithmetic mean Paragraph (2) obtained it, which amounted to (3.42) and a standard deviation of (0.95). Through Table (6), the results of the new entrant's dimension can be clarified, as follows:

Table (6) shows the mean and standard deviation for the items of the new entrants

\begin{tabular}{|l|l|l|}
\hline Paragraphs & mean & $\begin{array}{l}\text { standard } \\
\text { deviation }\end{array}$ \\
\hline New entrants face difficulties entering the field & $\mathbf{2 . 7 5}$ & $\mathbf{0 . 8 4}$ \\
\hline $\begin{array}{l}\text { The hospital relies on experience, which represents a competitive advantage that } \\
\text { new entrants cannot match }\end{array}$ & $\mathbf{2 . 7 1}$ & $\mathbf{0 . 8 9}$ \\
\hline $\begin{array}{l}\text { The hospital is unique in that its services are of high quality, which distinguishes } \\
\text { it from the customer's point of view }\end{array}$ & $\mathbf{3 . 3 9}$ & $\mathbf{1 . 1 6}$ \\
\hline Total new entrants & $\mathbf{2 . 9 5}$ & $\mathbf{0 . 9 6}$ \\
\hline
\end{tabular}

We notice from the previous table that the new entrants dimension achieved an arithmetic mean of (2.95), which is less than the hypothetical arithmetic mean and indicates that this dimension ranges in value around the value of the hypothetical mean in the researched organization, while the value of the standard deviation reached (0.96), it reflects the existence of Good harmony between the responses of the respondents of the research sample about the paragraphs of this dimension, and at the level of sub-paragraphs, paragraph (3) obtained the highest arithmetic mean, which amounted to (3.39), which is a high mean and a standard deviation of (1.16), and the lowest arithmetic mean Paragraph (2) obtained it, which amounted to (2.71), which is a moderate mean and a standard deviation of (0.89). The results of the alternative commodities dimension can be clarified through Table (7) as follows: 
Table (7) shows the mean and the standard deviation of the alternative commodity items

\begin{tabular}{|l|l|l|}
\hline Paragraphs & mean & $\begin{array}{l}\text { Standard } \\
\text { deviation }\end{array}$ \\
\hline Clients face difficulties in switching to alternative hospitals & $\mathbf{2 . 7 5}$ & $\mathbf{1 . 1 0}$ \\
\hline $\begin{array}{l}\text { Alternative hospitals achieve the required value from the patient's } \\
\text { point of view by price }\end{array}$ & $\mathbf{2 . 8 2}$ & $\mathbf{1 . 1 5}$ \\
\hline The hospital has services that are difficult to replicate & $\mathbf{3 . 8 2}$ & $\mathbf{1 . 1 8}$ \\
\hline Total alternative goods & $\mathbf{3 . 1 3}$ & $\mathbf{1 . 1 4}$ \\
\hline
\end{tabular}

It is evident from Table (7) that the alternative amplitude dimension achieved an arithmetic mean of (3.13) which is higher than the hypothesized arithmetic mean and indicates that this dimension ranges its value around the value of the hypothesis mean, while the value of the standard deviation reached (1.14), it reflects the existence of harmony Acceptable among the respondents of the research sample about the paragraphs of this dimension, and at the level of sub-paragraphs, paragraph (3) obtained the highest arithmetic mean, which amounted to (3.82), which is a high mean and a standard deviation of (1.18), while the lowest arithmetic mean was Paragraph No. (1) obtained it, which amounted to (2.75), which is a moderate average and with a standard deviation of (1.10). Through Table (8), the results of the buyers' bargaining power dimension can be clarified as follows:

Table (8) shows the arithmetic mean and standard deviation of the items of the bargaining power of buyers

\begin{tabular}{|l|l|l|}
\hline Paragraphs & mean & $\begin{array}{l}\text { standard } \\
\text { deviation }\end{array}$ \\
\hline $\begin{array}{l}\text { Clients have great flexibility in negotiating with the hospital in } \\
\text { order to lower the price depending on the services provided }\end{array}$ & $\mathbf{1 . 1 0}$ \\
\hline $\begin{array}{l}\text { The customer has full knowledge of the qualitative specifications of } \\
\text { the service }\end{array}$ & $\mathbf{3 . 5 7}$ & $\mathbf{1 . 1 6}$ \\
\hline $\begin{array}{l}\text { The wishes and needs of the patient are taken into consideration } \\
\text { when designing service policies in the hospital }\end{array}$ & $\mathbf{3 . 0 3}$ & $\mathbf{1 . 3 1}$ \\
\hline The total bargaining power of the buyers & $\mathbf{3 . 2 3}$ & $\mathbf{1 . 1 9}$ \\
\hline
\end{tabular}

It is evident from the previous table that the buyers' bargaining power dimension achieved an mean of (3.23) which is higher than the hypothetical arithmetic mean and indicates that the buyers bargaining power dimension ranges around the value of the hypothetical mean, while the value of the standard deviation reached (1.19), it reflects the existence of Acceptable harmony between the responses of the respondents of the research sample about the paragraphs of this dimension, and at the level of the sub-paragraphs, paragraph (1) obtained the highest arithmetic mean, which amounted to (3.57), which is a high mean and a standard deviation of (1.10), and the lowest arithmetic mean Paragraph No. (3) obtained it, which amounted to (3.03), which is a moderate mean and a standard deviation of (1.31). Through Table (9), the results of the bargaining power dimension of suppliers can be clarified as follows: 
Table (9) shows the mean and the standard deviation of the bargaining power clause for suppliers

\begin{tabular}{|l|l|l|}
\hline Paragraphs & mean & $\begin{array}{l}\text { Standard } \\
\text { deviation }\end{array}$ \\
\hline The hospital has more than one alternative in obtaining supplies & $\mathbf{3 . 0 3}$ & $\mathbf{1 . 1 7}$ \\
\hline There is a lot of competition between suppliers to deal with the hospital & $\mathbf{2 . 6 4}$ & $\mathbf{1 . 0 6}$ \\
\hline The hospital has a predetermined fortune to handle its suppliers & $\mathbf{2 . 8 5}$ & $\mathbf{1 . 2 0}$ \\
\hline Total bargaining power of suppliers & $\mathbf{2 . 8 4}$ & $\mathbf{1 . 2}$ \\
\hline
\end{tabular}

It is evident from Table (9) that the dimension of the bargaining power of suppliers achieved an arithmetic mean of (2.84) which is higher than the hypothetical arithmetic mean and indicates that this dimension ranges its value around the value of the hypothetical mean, while the value of the standard deviation reached (1.2) it reflects the existence of Acceptable harmony between the responses of the respondents of the research sample about the paragraphs of this dimension, and at the level of the sub-paragraphs, paragraph (1) obtained the highest arithmetic mean, which amounted to (3.03), which is a high mean and a standard deviation of (1.17), and the lowest arithmetic mean Paragraph No. (2) obtained it, which amounted to (2.64), which is a moderate mean and a standard deviation of (1.06). As for the total variable of Porter's model, it achieved an arithmetic mean of (3.14), which is higher than the hypothetical arithmetic mean, indicating that the Porter model in the researched organization ranges around the value of the hypothesis mean, while the value of the standard deviation reached (1.09), it reflects the existence of an acceptable harmony from The statistical aspect between the answers of the research sample about the paragraphs of this variable.

Second: Test the research hypotheses

In this paragraph, the research hypotheses will be tested by identifying the nature of the correlation and influence relationships between each of the explanatory and responsive variable, as shown in the results of Tables (10 and 11):

Table (10) Correlation relationship between the explanatory and responsive variable

\begin{tabular}{|l|l|l|l|l|}
\hline Independent variable & Dependent variable & $\begin{array}{l}\text { Correlation coefficient } \\
\text { value }\end{array}$ & Moral & Significance \\
\hline strategic vigilance & Porter's model & $* * \mathbf{0 . 6 7 7}$ & $\mathbf{0 . 0 1}$ & $\begin{array}{l}\text { There is a correlation } \\
\text { relationship }\end{array}$ \\
\hline
\end{tabular}

It is evident from Table (11) that there is a correlation relationship between the explanatory variable (strategic alert) and the response variable (Porter model) in the researched organization by (0.677), which is a very strong correlation, meaning that strategic alertness with its variables is strongly correlated with Porter's model. And with a significant level (0.01) and this indicates that the degree of confidence is $99 \%$ between the two variables, and based on these results, the first main hypothesis of the research can be accepted, which states (there is a statistically significant relationship between strategic awakening and the application of the Porter model of the five forces in the study organization). It is also possible through Table (11) to clarify the results of the effect of strategic vigilance in applying Porter's five forces model as follows: 
Table (11) shows the impact results between the research variables

\begin{tabular}{|c|c|c|c|c|c|c|c|c|c|c|}
\hline $\begin{array}{l}\text { Dependent } \\
\text { variable }\end{array}$ & Sig & $\mathbf{F}$ & $\mathbf{R}$ & Beta & R2 & Sig & $\mathbf{T}$ & \multicolumn{2}{|l|}{ B } & $\begin{array}{l}\text { Independ } \\
\text { ent } \\
\text { variable }\end{array}$ \\
\hline $\begin{array}{l}\text { Porter's } \\
\text { model }\end{array}$ & .01 & 21.964 & .677 & .677 & .458 & $\begin{array}{l}.404 \\
.000\end{array}$ & $\begin{array}{l}.848 \\
4 . .687\end{array}$ & $\begin{array}{l}.484 \\
.834\end{array}$ & $\begin{array}{l}\mathbf{A} \\
\mathbf{b}\end{array}$ & $\begin{array}{l}\text { strategic } \\
\text { vigilance }\end{array}$ \\
\hline
\end{tabular}

Table (11) indicates that the value of $(F=21.960)$ indicates the existence of an effect of the strategic alert variable in Porter's model. This explains the coefficient of determination $(\mathrm{R} 2=.458)$, which explains the ratio of (96\%) to the response variable from the explanatory variable. And through the same table, the constant value (a $=0.484$ ) can be observed, which means that there is an existence of the Porter model of (0.484) even if the value of strategic alertness is equal to zero, while the constant value $(B=0.834)$ indicates that the change in alertness The strategy will lead to a change of itself in the Porter model, and from Table (11) it was found that the level of significance is (0.01) and it confirms the presence of (strategic alertness in the Porter model), and the value of $t$ calculated (0.848) to interpret the value of the parameter (a The value of $t$ computed was (4.687) to explain the value of the coefficient of $\mathrm{B}$, and accordingly, based on the previous results, there is a justification for accepting the second main hypothesis, which states (there is a statistically significant effect of strategic alertness in the application of Porter's five forces model in the researched organization)

\section{The fourth topic: conclusions and recommendations}

\section{First: the conclusions}

This paragraph presents a number of conclusions reached by the research based on the results of the analysis, as

follows:

1. The research shows a correlation between strategic vigilance and Porter's competitive model in the surveyed hospitals, which confirms the importance of the dimensions of strategic alertness, which makes hospital management always ready in the face of unstable negative conditions.
2. It became clear that technological vigilance helps the researched hospital administration to improve services by having cadres that are difficult for competitors to imitate.

3. Hospital management monitors its competitors from governmental and private hospitals by collecting and analyzing information about them and analyzing the environment of its competitors on a permanent basis to raise the quality of its services and obtain a good market share.

4. Marketing vigilance has a positive effect in providing the necessary resources and medicines. The senior management within the investigated hospitals monitors and monitors circumstantial events through the environmental information they receive and works to assess their risks and confront them with awareness.

\section{Second: Recommendations}

In this paragraph the researchers try to present a set of recommendations to reinforce the conclusions reached by the research, as follows:

1. The management of the surveyed hospitals should focus on strategic vigilance, as it is one of the most important means to improve Porter's model and to make hospital management on standby in the face of emergency circumstances.

2. Hospital management should shed light on technological vigilance to follow the development in the field of medical technology by working companies with leading hospitals in their field of specialization to ensure that they cope with the challenges of competitors.

3. The necessity for the hospital administration to provide sufficient nursing staff to ensure the provision of a high level of services provided to its customers.

4. Emphasizing the importance of marketing vigilance in securing the hospital's researched needs of the necessary resources, medicines and a sufficient number of suppliers to ensure continuity of services. 


\section{SOURCES}

1- Ibrahim, Hussein Ali (2017) Evaluation of Nursing Services According to Strategic Vigilance (Applied Research at Shahid Ghazi Hariri Hospital), Master of Nursing Administration, University of Baghdad. 2- Ibrahim, Uday Ibrahim Abbas (2006) Environmental Analysis and its Impact on Choosing an Organizational Adaptation Strategy, Master Thesis, College of Management and Economics, University of Baghdad, unpublished research. 3- Al-Jader, Soheir Adel (2007), the relationship between strategic analysis and the strategy of the alliance and their impact on organizational performance, a doctoral thesis submitted to the College of Administration and Economics, University of Baghdad

4- Al-Sakal, Ahmad, (2004) Strategic Analysis and its Impact on Business Options and Competitive Advantage, a Case Study in the General Company for Electrical Industries, $\mathrm{PhD}$ thesis, University of Baghdad. 5- Ameerah, Mohat, (2014), "The Impact of Strategic Vigilance on Improving Marketing Performance, Case Study of Algeria Telecom Corporation - Mila Branch", MA Research in Facilitation Sciences, Faculty of Economic and Commercial Sciences and Facilitation Sciences, University of Mohamed Khudair - Biskra 6- Hussein, Intisar Aziz (2010), The Impact of Strategic Analysis on Service Quality, An exploratory study of the performance of workers in the sample of Iraqi banks, Master Thesis, unpublished, College of Administration and Economics, AlMustansiriya

University. 7- Hussein, Intisar Aziz (2015), “The Relationship between Strategic Vigilance and Marketing Culture and Its Impact on Marketing Management Directions" PhD thesis, College of Administration and Economics, Al-Mustansiriya University. 8- Hamdan, Khaled Muhammad and Idris, Wael Muhammad (2009) Strategy and Strategic Planning a Contemporary Approach, Al-Yazuri Publishing and Distribution, Amman. 9- Omar, Shabounieh (2007), "Information Monitoring Systems in Economic Institutions: The Role of the Information Specialist / Case Study of Somic Corporation, Sonatrach, Skikda", Master Thesis in Library Science submitted to the Faculty of Humanities and Social Sciences, University of Mentouri, Algeria. 10- Lamia, Helmy (2009), "The Role of Strategic Vigilance and Economic Intelligence in Enhancing the Competitiveness of Small and Medium Enterprises", Master Thesis in Economic Sciences and Facilitation Sciences, submitted to the University of Mohamed Bougara Boumerdes, Algeria. 11- Karoumi, Saeed, Omarsti, Ahmed (2010), "The importance of strategic vigilance in improving the strategic and competitive decisions of the enterprise," the Fourth International Forum on: Competition and Competitive Strategies of Industrial Enterprises.

12- Omar, Marwa Jamal (2017) The extent of managers 'awareness of the importance of strategic vigilance, Journal of Financial $\begin{array}{llllll}\text { and Accounting } & \text { Studies, } & \text { Issue } & \text { Issue } & 40\end{array}$ 13- Mahmoud, Zaid Khawam (2017) Strategic Vigilance and Its Impact on Organizational Success An exploratory research in Al-Faris State Company, Journal of Economic and Management Sciences, Issue 96, Volume 23 14- Morsi, Nabil Muhammad, and Salim, Ahmed Abdel Salam (2007), "Strategic Management”, Modern University Office. 15- Nour El-Abidine, Goujil (2012) The role of strategic vigilance in rationalizing communication between the institution and its surroundings, a field study in the unit of two mills of Sidi Arghis Oum El Bouaghi, MA thesis, Algeria 16- Youssef, Boumediene (2010), "The Vigilance Mechanism and Strategic Intelligence: A Tool to Face Future Challenges and One of the Competitiveness Factors", The Fourth International Forum on: Competition and Competitive Strategies for Industrial Enterprises Outside the Hydrocarbon Sector in Arab Countries 